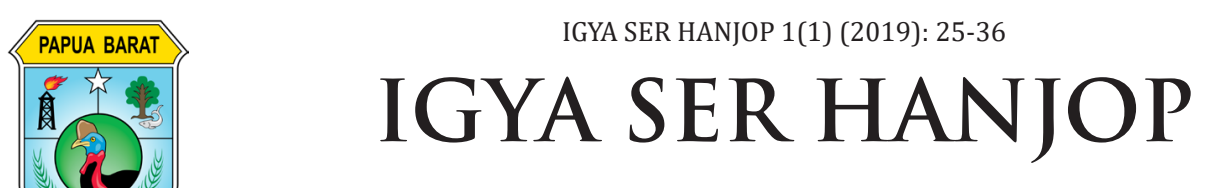

p-ISSN: 2716-0491

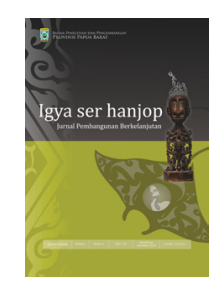

\title{
KEANEKARAGAMAN KATAK DAN REPTIL dari Areal Koperasi Masyarakat Adat Papua Kami-Nassey, Teluk Wondama, Papua Barat
}

\author{
Keliopas Krey ${ }^{1 *}$, Hendrik Burwos ${ }^{2}$, \\ ${ }^{1}$ Universitas Papua Manokwari \\ ${ }^{2}$ Pusat Penelitian Lingkungan Hidup, Universitas Papua \\ Jl. Gn. Salju, Manokwari Barat, Amban, Manokwari, Papua Barat 98314
}

Dikirim: 15 September 2019; Direvisi: 12 November 2019; Disetujui: 18 Desember 2019

\begin{abstract}
Herpetofauna (Amphibian and Reptile) data collection in the Kami-Nassey Papua Indigenous People's Cooperative area in Teluk Wondama District has been implemented for seven days (1-7 August 2019) as part of negotiations on high conservation areas. Literacy in lowland primary forest habitats to hills, secondary forest habitat and secondary forest around nurseries. This research uses VAES (Visual Audio Encounter Survey) and Patch sampling methods. Reptile and amphibian species are collected directly using hands during the day and night. Direct interviews with several community members about reptile and amphibian species that are often encountered may even be done intentionally or unintentionally. A total of 36 species of herpetofauna have been recorded during this study, consisting of 16 species of frogs and 20 species of reptiles. Of the total species found as many as 3 main land endemic species of the island of Papua, 23 main land rendemic species include satellite islands, while 9 species of distribution are quite extensive. In addition, 11 sepsies are registered in CITES, and 5 protected reptile species are based on the Republic of Indonesia's Ministry of Environment and Forestry Regulation. Although intensive observations have been made, they include some species that need to exist and have not been added to this survey. Micro climatic conditions (such as rainy days, temperature and humidity) and the life of each species greatly affect the findings of frog and reptile fauna in this study.
\end{abstract}

Keywords: conservation, habitat, species, herpetofauna, nikiwar

Intisari

Pengumpulan data Herpetofauna (Amfibi dan Reptil) pada arealKoperasi Masyarakat Adat Papua KamiNassey di Kabupaten Teluk Wondama telah dilaksanakan selama tujuh hari (1 -7 Agustus 2019) sebagai bagian dari identifikasi kawasan-kawasan bernilai konservasi tinggi.Penelitian berlokasi di habitat hutan primer dataran rendah hingga perbukitan, habitat hutan sekunder dan hutan sekunder di sekitar persemaiankopermas. Penelitian ini menggunakan metode VAES (Visual Audio Encounter Survey) dan Patch sampling. Spesies-spesies reptil dan amfibi dikoleksi langsung menggunakan tangan pada siang dan malam hari. Wawancara langsung dengan beberapa anggota masyarakat setempat untuk mengetahui spesies reptil dan amfibi yang sering dijumpai bahkan mungkin dibunuh secara sengaja maupun tidak sengaja. Sebanyak 36 spesies herpetofauna telah terdata selama penelitian ini, yaitu terdiri dari16 spesies katak dan 20spesies reptil. Dari total spesies yang dijumpai terdapat sebanyak 3 spesies endemik daratan utama Pulau Papua, 23 spesies rendemik daratan utamatermasuk pulau satelit, sedangkan 9 spesies distribusi cukup luas. Selain itu, 11 sepsies terdaftar dalam CITES, dan 5 spesies reptil lindungan berdasarkan Permen KLHK Republik Indonesia. Walaupun observasi telah dilakukan secara intensif, namun terdapat beberapa spesies yang diduga ada dan belum tercatat dalam survey ini. Kondisi iklim mikro (seperti hari hujan, suhu dan kelembaban udara) dan kebiasaan hidup setiap jenis sangat mempengaruhi hasil temuan fauna katak dan reptil dalam penelitian ini.

Kata Kunci: konservasi, habitat, spesies, herpetofauna, nikiwar

* Korespondensi Penulis
Phone : +6281245236527
Email : keliopaskrey@ymail.com
(C) 2019 Keliopas Krey, Hendrik Burwos Ciptaan disebarluaskan di bawah Lisensi Creative Commons Atribusi NonKomersial-Berbagi Serupa 4.0 Internasional. 


\section{LATAR BELAKANG}

Herpetofauna atau reptil dan amfibi merupakan dua kelas dari filum Chordata yang sering dipelajari secara bersama dalam kelompok ilmu herpetology. Amfibidi Papua terdiri dari hanya satu ordo (bangsa) yaitu ordo anura (katak), sedangkan reptil terdiri dari ordo Testudinata (Kura-kura dan penyu), Crocodylia (Buaya) dan Squamata (kadal, ular dan kadal cacing). Total spesies katak dan reptil papua adalah 371. Data ini masih jauh di bawah jumlah spesies di negara tentangga Papua New Guinea (PNG) yang mencapai 553 spesies (Allen Allison, 2006) yang dapat dilihat pada Tabel 1.

Tabel 1.

Data Spesies Reptil dan Amfibi yang Telah Direkam

\begin{tabular}{|c|c|c|c|}
\hline \multirow{2}{*}{ No. } & \multirow{2}{*}{ Kelompok } & Jumlah & spesies \\
\hline & & Papua & PNG \\
\hline 1. & Katak & 130 & 248 \\
\hline 2. & $\begin{array}{c}\text { Kura-kura dan } \\
\text { penyu }\end{array}$ & 15 & 16 \\
\hline 3. & Buaya & 2 & 2 \\
\hline 4. & Kadal & 141 & 183 \\
\hline 5. & Ular & 83 & 103 \\
\hline \multicolumn{2}{|r|}{ Total } & 371 & 553 \\
\hline
\end{tabular}

Sumber: Allison (2007)

Jumlah spesies katak dan reptil di Papua adalah 371 (Allen Allison, 2006). Dalam kurung waktu 12 tahun tentunya jumlah spesies di Papua telah mengalami penambahan spesies baru lainnya seperti dari Raja Ampat ditemukan satu Cyrtodactylus (Oliver et al., 2008) dan dua Cophyxalus (Günther et al., 2015) juga katak baru Litoria gasconi dari Foja (Richards et al., 2002).

Regulasi terbaru yang tertuang dalam Peraturan Menteri KLHK No P.106 Tahun 2018 menunjukkan bahwa sebanyak 37 spesies reptil lindungan di Indonesia, sedangkan untuk taksa amfibi terdapat satu spesies lindungan yakni Leptophryne cruentata, kodok merah dari pulau Jawa. Dari jumlah reptil lindungan tersebut sebanyak 16 (43\%) spesies memiliki daerah penyebaran di New Guinea (Papua hingga PNG). Tabel 2 menunjukkan data reptil lindungan yang tersebar di wilayah tanah Papua.
Tabel 2.

Reptil Lindungan yang Memiliki Daerah Penyebaran di Papua

\begin{tabular}{ll}
\hline Nama IImiah & Nama Indonesia \\
\hline Caretta caretta & Penyu tempayan \\
Carettochelys insculpta & Kura-kura Irian \\
Chelodina novaeguineae & Kura Irian leher panjang \\
Chelonia mydas & Penyu hijau \\
Chlamydosaurus kingii & Soa payung \\
Morelia viridis & Sanca hijau \\
Crocodylus novaeguineae & Buaya air tawar Irian \\
Crocodylus porosus & Buaya muara \\
Dermochelys coriacea & Penyu belimbing \\
Eretmochelys imbricata & Penyu sisik \\
Lepidochelys olivacea & Penyu ridel \\
Natator depressa & Penyu pipih \\
Varanus indicus & Biawak Maluku \\
Varanus prasinus & Biawak hijau \\
Varanus reisingeri & Biawak Misol \\
Varanus boehmei & Biawak Waigeo \\
\hline
\end{tabular}

Sumber: Permen KLHK Nomor P.106 tahun 2018

Kelengkapan data lapangan tentang keanekaragaman reptil dan amfibi sangat penting dan mendukung manajemen hutan terkait area-area bernilai konservasi tinggi. Hal ini berkaitan dengan peruntukan data herpetofauna yang dapat dijadikan parameter untuk melihat indikasi kerusakan atau perubahan-perubahan lingkungan pada waktu-waktu mendatang. Dari data-data keanekaragaman herpetofauna tersebut, kita dapat mempelajari spesies-spesies hewan yang menghilang (migrasi atau punah) karena kerusakan habitatnya.

Tujuan dari penelitian ini adalah untuk mengidentifikasi spesies herpetofauna serta menilai kategori nilai konservasi tinggi spesies herpetofauna yang terdapat pada arealKopermas Kami-Nassey, Kabupaten Teluk Wondama.

\section{Metode}

Penelitian ini telah dilaksanakan selama 7 hari pada Agustus 2019 di konsesi Koperasi Masyarakat Adat Papua Kami-Nassey, Kabupaten Teluk Wondama, Provinsi Papua Barat. Habitat alami yang disurvei (Tabel 3) meliputi hutan sekunder berbukit dataran rendah di sekitar area persemaian pala, hutan primer berbukit dataran rendah di dekat wilayah kampung Idoor dan Torembi, dan area kartz (jalan menuju arah kampung Idoor). 
Sungai, rawa sagu, hingga aliran air di bawah jembatan juga diobservasi. Data-data reptil dan amfibi juga dicatat saat perjalanan melintasi hutan-hutan antar kampung.

Tabel 3.

Lokasi Pengumpulan Data Satwa Liar

\begin{tabular}{cccc} 
Lokasi & Koordinat & $\begin{array}{c}\text { Altitud } \\
(\mathrm{m})\end{array}$ & $\begin{array}{c}\text { Jumlah } \\
\text { Transek }\end{array}$ \\
\hline \multirow{2}{*}{ Idoor } & S: 227.905 & & \\
& E: 13406.350 & 28 & 1 \\
\hline \multirow{2}{*}{ Karst } & S: 229.104 & & \\
& E: 13407.273 & 177 & 1 \\
\hline \multirow{2}{*}{ Persemaian } & S: 225.821 & & \\
\hline \multirow{2}{*}{ Torembi } & E: 13407.908 & 200 & 1 \\
\hline & S: 223.451 & & \\
\hline
\end{tabular}

Penelitian ini menggunakan metode VAES (Visual Audio Encounter Survey) dan patch sampling. Transek pengamatan dibuat sepanjang $1 \mathrm{Km}$ pada setiap site sampel dan setiap transek dilalui pada siang dan malam hari dengan menggunakan teknik time searching. Observasi dan penangkapan spesies reptil dan katak pada siang dan malam hari dilakukan secara bebas pada tiap transek dengan batasan waktu pencarian (time searching) 3-4 jam. Pengamatan reptil difokuskan pada pagi hari saat reptil berjemur (jam 7 sampai 11 pagi) di dalam hutan, sekitar pinggir sungai kecil dan daerah terbuka lainnya. Reptil nokturnal dicari di sepanjang transek bersamaan dengan survei katak.

Survei katak secara aktif dilakukan pada malam hari mulai sekitar jam 19.00 sampai jam 23.00 menggunakan bantuan senter dengan metode penjumpan visual dan pendengaran suara di daerah sekitar sepanjang sungai kecil dan besar, di sekitar kolam dan rawa, dan daerah berhutan untuk mencari katak yang besifat akuatik, terrestrial, fusorial (hidup dalam lubang tanah) dan arboreal. Pencarian dilakukan oleh 3-4 orang per malam dengan secara seksama mengamati lingkungan yang mungkin menjadi mikrohabitat katak. Setiap reptil dan katak yang ditemukan selanjutnya ditangkap dan dilakukan pemotretan sebelum reptil atau katak tersebut dilepas atau dipreservasi. Seluruh koleksi spesimen yang diperoleh dalam penelitian ini disimpan di laboratorium zoology, Universitas Papua.

Selain dengan pendekatan morfologi, suara katak juga dijadikan petunjuk pencarian terutama bagi secretive semifossorial frog yang hidup tersebunyi pada lubang-lubang di tanah, tumpukan kayu lapuk, lubang pohon, semak, serasah, genangan air dan aliran sungai. Wawancara langsung dengan masyarakat setempat juga dilakukan untuk mengetahui herpetofauna yang sering dijumpai, dipelihara bahkan mungkin dibunuh secara sengaja maupun tidak.

Pencatatan data-data visual seperti tipe dan kondisi habitat, ketinggian tempat, cuaca serta waktu penangkapan dilakukan guna melengkapi data ekologi semua herpetofauna yang ada. Data lapangan yang diperoleh baik dari pengamatan transek, pendengaran suara katak maupun catatan data spesies sepanjang perjalanan antar lokasi, peliharaan masyarakat maupun wawancara digunakan untuk menganalisa aspek-aspek berikut:

- Jumlah spesies dan famili herpetofauna

- Keanekaragaman dan Kemerataan spesies herpetofauna. Analisa ini menggunakan Indeks Shannon Wieners $\left(\mathrm{H}^{\prime}\right)$ dan Evenness (E)

- Endemisitas dan distribusi geografi herpetofauna

- Untuk menguraikan signifikansi nilai konservasi tinggi spesies dari aspek taksonomi, keendemikan, keterbatasan kemampuan menyebar, habitat penting dan spesifik serta sensitifitas terhadap perubahan lingkungan

- Target dan Status Konservasi Spesies

- Pendekatan ini berbasis pada analisis nilai konservasi tinggi spesies reptil dan amfibi yang signifikan secara global, nasional, dan regional. Analisis ini mengasumsikan bahwa target spesies reptil dan amfibi dengan status konservasi menurut IUCN, perdagangan menurut CITES, dan perlindungan menurut Permen KLHK Nomor P.106 tahun 2018 adalah memiliki nilai konservasi tinggi yang signifikan.

\section{HaSil dAN PEMbahasan}

\section{A. Spesies Amfibi dan Reptil yang Ditemukan}

Sebanyak 36 jenis amfibi dan reptil berhasil diidentifikasi dalam penelitian ini. Amfibi dan reptil yang teridentifikasi (Gambar 1) terdiri 
dari 16 spesies katak (44,44\%), 11 spesies kadal (30,56\%), 6 spesies ular (16,67\%), 2 spesies buaya $(5,56 \%)$ dan 1 spesies kura$\operatorname{kura}(2,78 \%)$.

Data spesies reptil dan katak yang dihimpun dalam penelitian ini adalah data seluruh hasil temuan lapangan yang diperoleh melalui perjumpaan langsung dihabitatnya, peliharaan, maupun wawancara dengan masyarakat. Sedikitnya waktu pengamatan dan kondisi iklim mikro (seperti sedikitnya hari hujan, suhu dan kelembaban udara) dan kebiasaan hidup setiap spesies sangat mempengaruhi hasil temuan katak dan reptil dalam penelitian ini.

Jumlah amfibi dan reptil yang ditemukan di area Kopermas Kami-Nassey ini relatif lebih rendah jika dibandingkan dengan area lainnya di sekitar Teluk Bintuni seperti area HPH PT. Wananggala Utama, PT. Manokwari Mandiri Lestari dan BP Tangguh. Walaupun demikian data-data yang terdapat pada areal Kopermas Kami-Nassey memberikan gambaran umum tentang kehadiran dan penyebaran spesies reptil dan amfibi di kawasan Teluk Wondama hingga Teluk Bintuni. Gambar 2 memperlihatkan perbandingan jumlah spesies amfibi dan reptil pada beberapa area di sekitar Teluk Bintuni yang telah diteliti.

\section{B. Keanekaragaman Spesies Katak dan Reptil}

Keanekaragaman spesies katak dan reptil berdasarkan empat lokasi kajian menunjukkan kondisi yang berbeda-beda. Rekapitulasi level keanekaragaman $\left(\mathrm{H}^{\prime}\right)$ dan kemerataan (E) spesies katak dan reptile pada empat lokasi penelitian disajikan dalam Tabel 4.

Kisaran keanekaragaman $\left(\mathrm{H}^{\prime}\right)$ spesies katak pada empat lokasi penelitian adalah 0,82,5. Lokasi Persemaian memiliki $\mathrm{H}^{\prime}$ tertinggi yakni mencapai 2,5 sedangkan terendah pada kawasan kartz sebesar 0,8. Lokasi Kartz sangat miskin spesies katak dari berbagai family sehingga keanekaragamannya rendah. Kisaran nilai $\mathrm{H}^{\prime}$ katak menunjukkan bahwa keanekaragaman katak untuk seluruh wilayah kajian termasuk kategori rendah hingga sedang $(<3)$. Kondisi yang sama pada taksa reptil dengan nilai keanekaragaman spesies pada empat lokasi menunjukkan kategori sedang dengan kisaran $\mathrm{H}^{\prime}=1,8-2,1$. Rendahnya keanekaragaman spesies kedua taksa katak dan

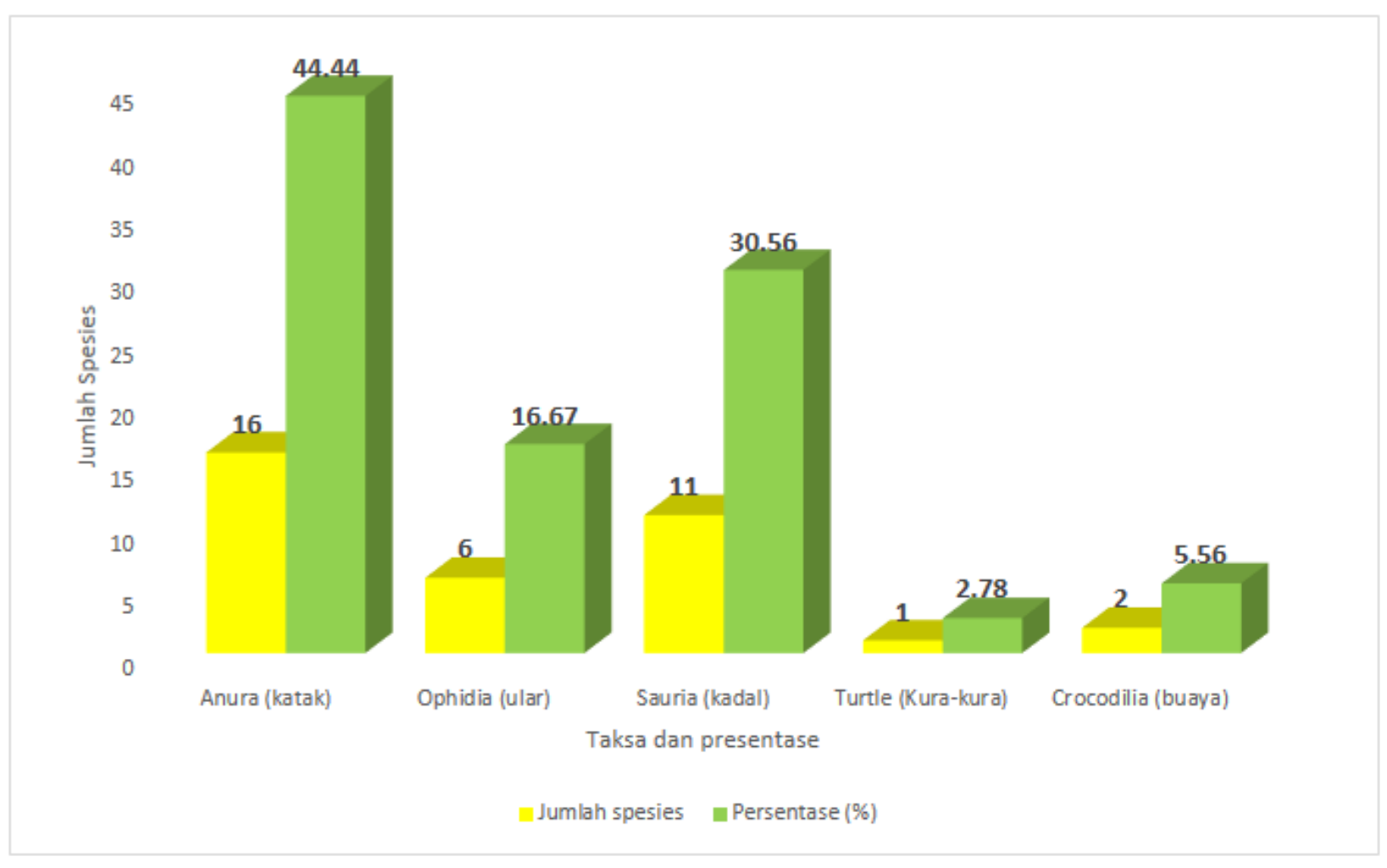

Gambar 1. Jumlah dan Presentase Spesies Amfibi dan Reptil yang Ditemukan 


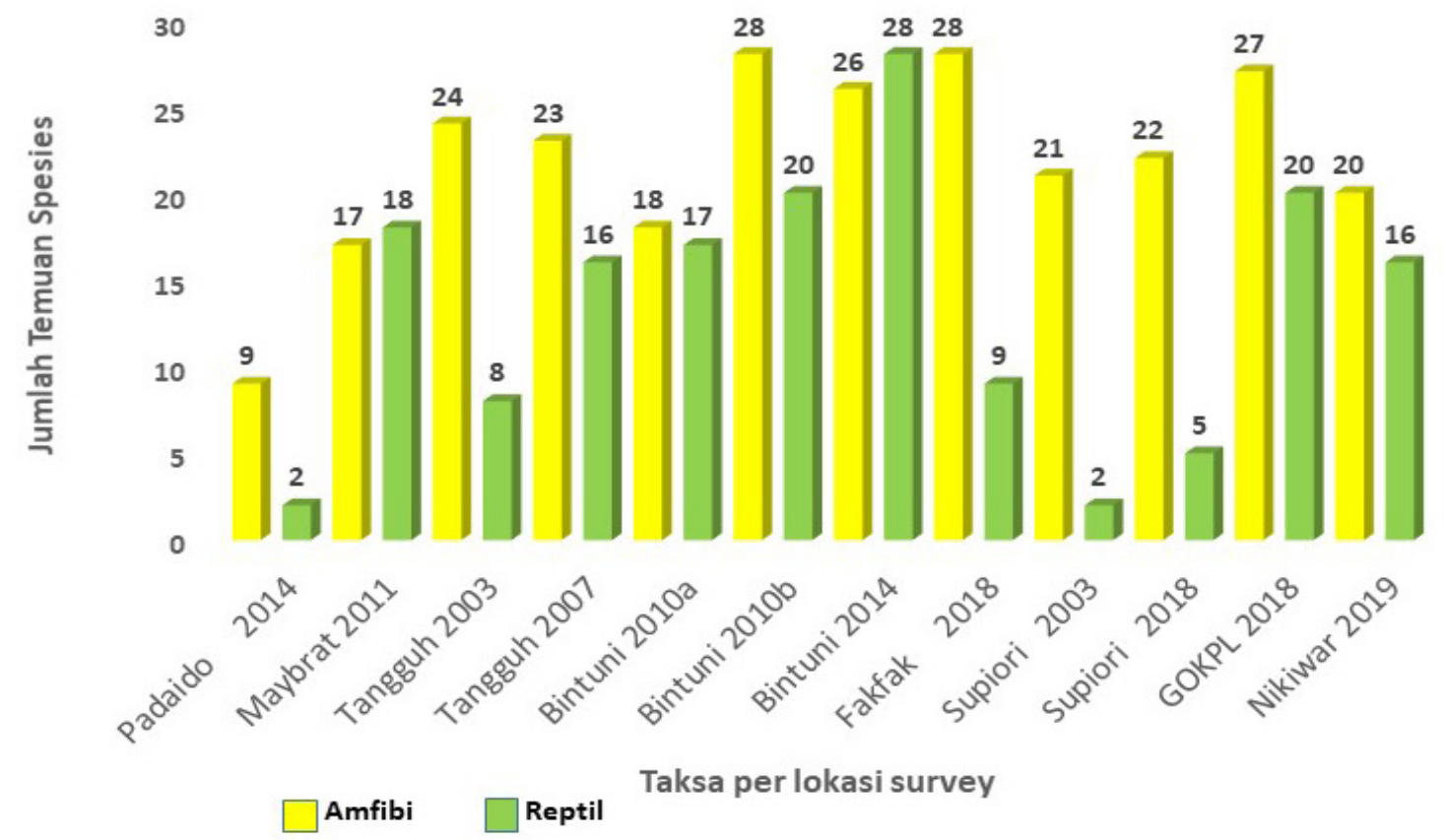

Gambar 2. Perbandingan Spesies Amfibi dan Reptil

yang Telah Diteliti Selama 16 Tahun pada 12 Lokasi Biogeografi Tanah Papua

Keterangan :

Nikiwar 2019: Penelitian ini; Supiori 2018: Krey, 2018; Supiori 2003: Kurniati, 2003; Fakfak 2018: Krey, 2018; Bintuni 2014: PT. Wukirasari, Krey 2014; Bintuni 2010a: PT. Wananggala Utama (Mayabubun 2010); Bintuni 2010b: PT. MML (Krey dan Dumutu 2010); Tangguh 2003: BP 2003; Tangguh 2007: Kusrini 2007; Maybrat 2011: PT. Bima Cakrawala Nusantara (BCN); Padaido 2014: EBA Mios Mangguandi, Krey 2014.

reptil diduga disebabkan kondisi iklim (suhu, kelembaban, dan hari hujan) yang relativ panas saat pengumpulan data.

Evenness atau keseragaman menunjukkan keseimbangan komunitas yaitu ukuran kesamaaan jumlah individu antar spesies dalam suatu komunitas. Indeks Kemerataan (Index of Evenness) berfungsi untuk mengetahui kemerataan setiap jenis dalam setiap komunitas yang dijumpai pada empat lokasi kajian. Kemerataan jenis memiliki nilai indikator $\mathrm{E}=1$. Apabila nilai $\mathrm{E}=1$ berarti pada habitat tersebut tidak ada jenis satwa liar yang mendominasi komunitasnya. Umumnya seluruh komunitas katak dan reptil pada keempat lokasi menunjukkan nilai E mendekati angka 1 (0,70-0,91). Komunitas reptil ( $\mathrm{E}=0$,70,91 ), dan amfibi dengan nilai $E=0,72-0,90$.

Tabel 4.

Keanekaragaman $\left(\mathrm{H}^{\prime}\right)$ dan Kemerataan (E) Jenis Satwa Liar

\begin{tabular}{cccccccccc}
\hline \multirow{2}{*}{ Lokasi } & \multicolumn{2}{c}{ Katak } & \multicolumn{2}{c}{ Reptil } & \multicolumn{2}{c}{ Katak } & \multicolumn{2}{c}{ Reptil } \\
\cline { 2 - 10 } & Spesies & Individu & Spesies & Individu & H' & E & H' & E \\
\hline Idoor & 11 & 49 & 11 & 22 & 2.13 & 0.88 & 2.1 & 0.87 \\
\hline Torembi & 12 & 79 & 13 & 37 & 2.1 & 0.84 & 1.8 & 0.70 \\
\hline Kartz & 3 & 9 & 8 & 12 & 0.8 & 0.72 & 1.9 & 0.91 \\
\hline Persemaian & 16 & 108 & 13 & 48 & 2.5 & 0.90 & 1.8 & 0.70 \\
\hline
\end{tabular}




\section{Kekayaan Spesies Katak dan Reptil}

Hutan berbukit rendah dan hutan dataran yang merupakan sub-ekosistem dari Hutan Hujan Dataran Rendah (lowland rain forests) memberikan ciri tersendiri dalam hal penyebaran dan pemilihan habitat oleh spesies reptil maupun amfibi. Kekayaan dan keanekaragaman spesies amfibi dan reptil pada setiap site sampel berbeda-beda. Empat site sampel meliputi area hutan sekitar kampung Idoor yang mewakili habitat hutan primer (flat area) dan bukit kartz dataran rendah. Site sampel ketiga adalah area hutan primer Torembi, dan yang keempat adalah hutan sekunder sekitar persemaian. Data yang diplotkan dalam Gambar $\mathbf{3}$ menunjukkan kekayaan spesies tiap site sampel, sedangkan kekayaan spesies per taksa yang amfibi dan reptil per famili dapat dilihat pada Gambar 4.

\section{Uraian Famili Amfibi dan Reptil}

Sebanyak lima takson spesies amfibi dan reptil menghuni habitat-habitat alami di area Kopermas Kami-Nassey. Rekapitulasi spesies amfibi tiga famili katak, empat famili kadal, dua famili ular, buaya dan kura-kura masingmasing satu famili (Gambar 4) dan distribusi takson per lokasi site sampel (Tabel 5).

Amfibi (Katak) hidup di habitat-habita alamiah sepanjang delta aliran-aliran sungai dalam hutan hingga tepian jalan. Terdapat 4 famili asli (native families) katak di New Guinea yaitu Hylidae, Microhylidae, Ranidae dan Myobatrachidae (Krey, 2019). Spesies katak dari famili Myobatrachidae tidak dijumpai dalam penelitian ini. Terdapat lima spesies endemik New Guinea dari family Myobatrachidae (Allen Allison, 2006) dan diduga satu spesies diantaranya yakni Lecriodus melanopyga kemungkinan ada di area Kopermas Kami-Nassey. Kebanyakan spesies katak dari ketiga familiyang dijumpai dalam penelitian inimenghuni habitat yang bervegetasi rapat.

Salah satu famili dari taksa ular yang tidak dijumpai dalam penelitian ini adalah famili Boidae. Famili ini di Papua diwakili oleh hanya dua spesies endemik New Guinea (termasuk pulau sekitar) yakni Candoia carinata (CITES II) dan C. aspera. Kedua spesies ini diduga ada di area Kopermas Kami-Nassey. Spesies ini dijumpai juga pada penelitian di area Tangguh (BP 2003). Area Kopermas Kami-Nassey menjadi habitat alami satwa liar reptil yang dilindungi.

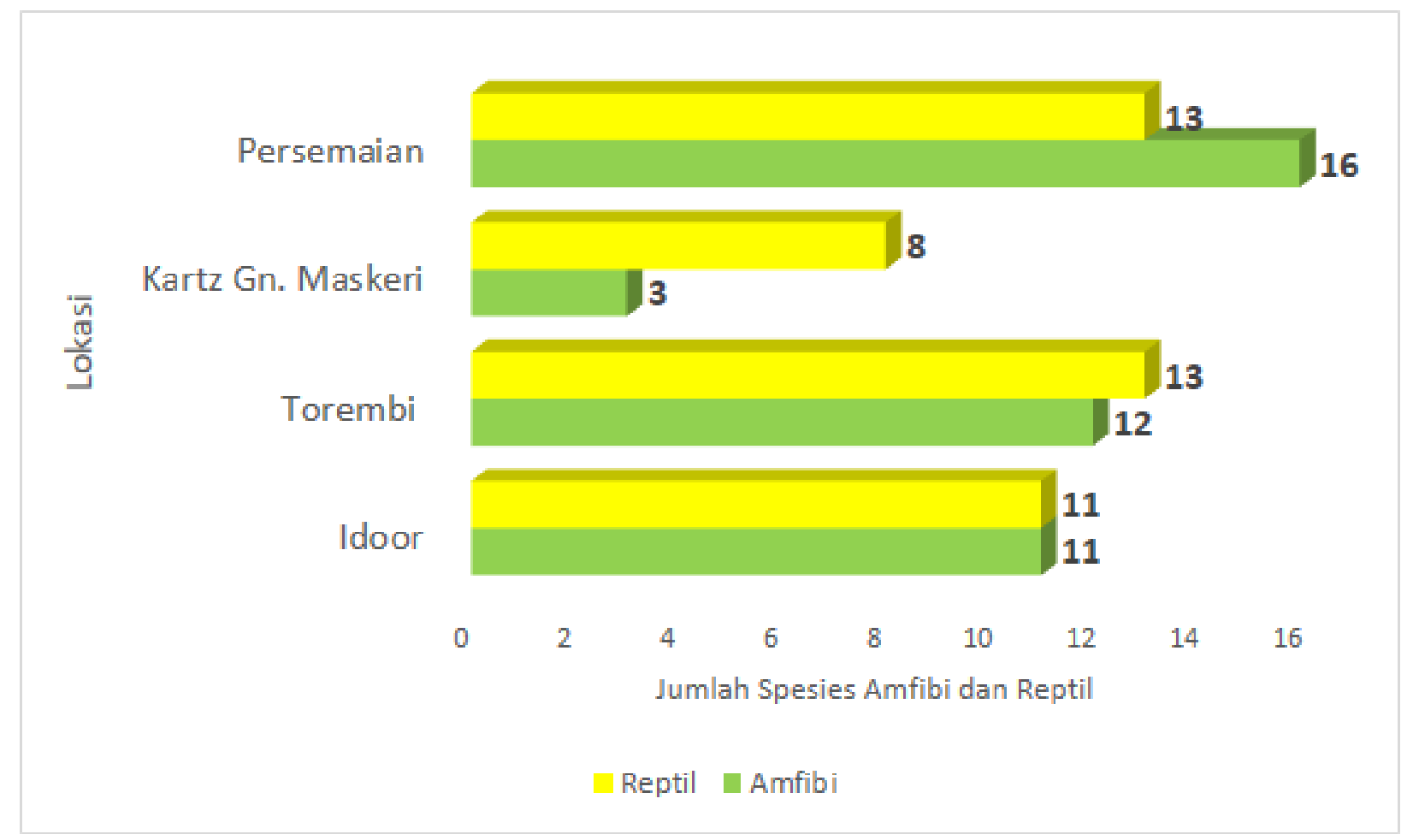

Gambar 3. Data Jumlah Spesies Katak dan Reptil per Lokasi Survey 


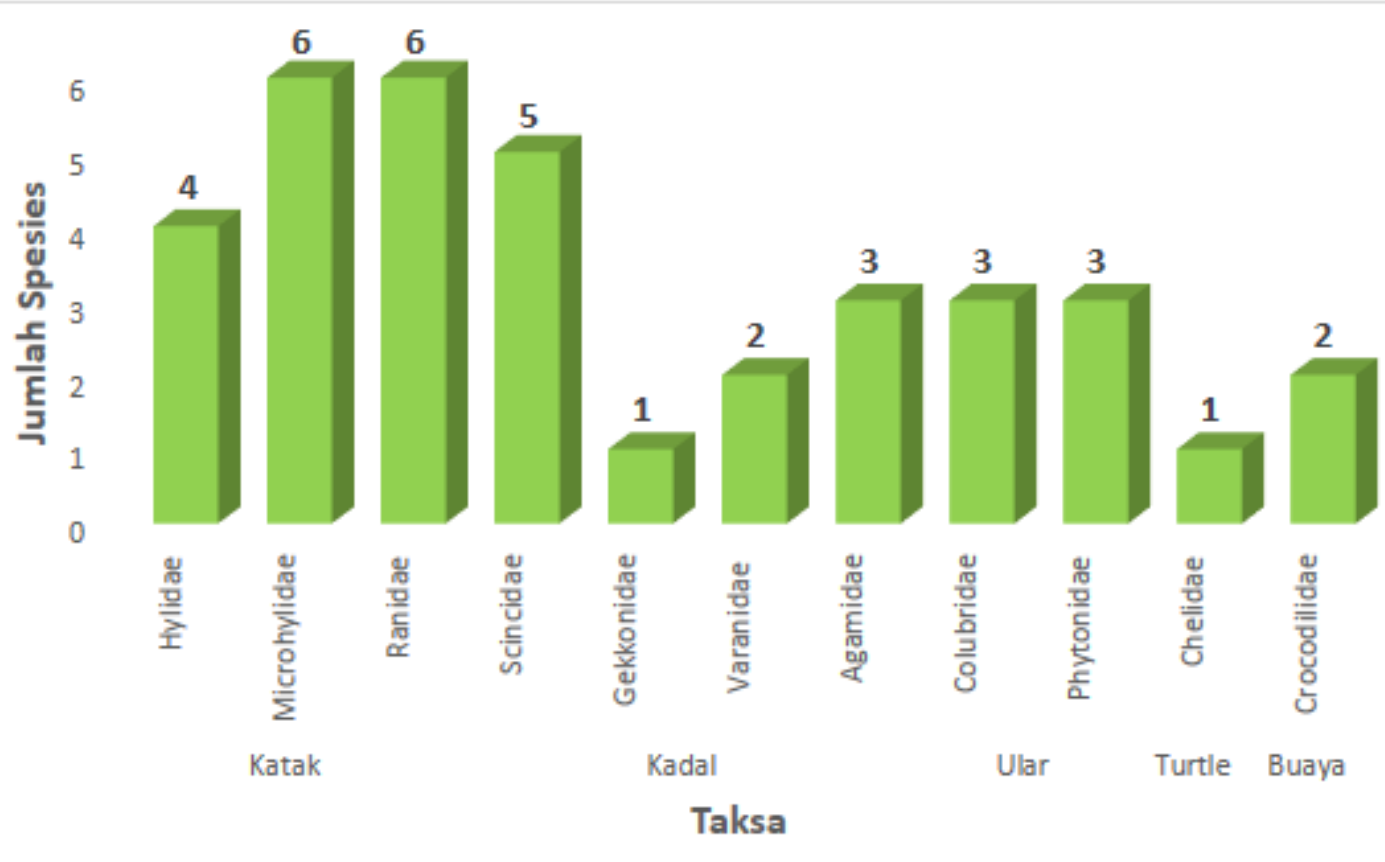

Gambar 4. Kekayaan spesies berdasarkan taksa

Data pada Tabel 6 menunjukkan spesiesspesies reptil lindungan yang tersebar pada keempat site sampel. Data status konservasi dan perkembangan informasi populasi disusun berdasarkan data Red List IUCN 2019. Degradasi layanan fungsi habitat akibat pembukaan kanopi hutan yang berlebihan, erosi yang menyebabkan dampak turunan pada kekeruhan air sungai, kali kecil, kolam dan rawa akan menjadi gangguan dan ancaman jangka panjang bagi spesies-spesies ini. Dilain sisi, struktur kompleks ekologi dari Hydrologi, iklim (micro-climate) termasuk biologi amfibi sangat mempengaruhi komposisi spesies dan kesehatan populasi amfibi dimasa mendatang. Walaupun dalam data red list IUCN 2019 semua spesies katak yang dijumpai berstatus least concern namun perlu diwaspadai. Katak Litoria genimaculata misalnya saat ini memiliki populasi yang sedang menurun (decreasing) (Harry Hines, 2004).

\section{E. Hylidae (Katak Pohon)}

Hylidae di New Guinea diwakili oleh hanya dua genus yaitu Litoria dan Nyctimystes. Tyler (1999) disitasi Allison (2006) menyatakan bahwa tidak terdapatnya famili Hylidae di region Southern Asia dan adanya family

Tabel 5.

Rekapitulasi Spesies Amfibi dan Reptil Per Lokasi

\begin{tabular}{ccccc}
\hline Takson & Idoor & Torembi & Gunung Karts & Persemaian \\
\hline Ophidia (ular) & 3 & 4 & 1 & 3 \\
\hline Sauria (kadal) & 6 & 7 & 6 & 10 \\
\hline Turtle (Kura-kura) & 1 & 1 & 0 & 0 \\
\hline Crocodilia (buaya) & 1 & 1 & 0 & 0 \\
\hline Anura (katak) & 11 & 12 & 3 & 29 \\
\hline Total & 22 & 25 & 9 & 16 \\
\hline
\end{tabular}


Tabel 6.

Status Konservasi Spesies Katak dan Reptil yang Ditemukan

\begin{tabular}{|c|c|c|c|c|c|c|c|c|}
\hline \multirow[b]{2}{*}{ Spesies } & \multirow[b]{2}{*}{$\begin{array}{l}\text { Endemik } \\
\text { Mainland }\end{array}$} & \multirow[b]{2}{*}{ P.106 } & \multirow[b]{2}{*}{ IUCN } & \multirow[b]{2}{*}{ CITES } & \multicolumn{4}{|c|}{ Lokasi } \\
\hline & & & & & 흠 & 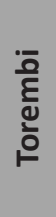 & 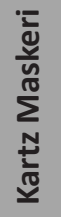 & 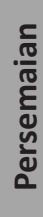 \\
\hline Crocodylus novaeguineae & $\mathrm{Y}$ & $\mathrm{Y}$ & LC/Stabel & II & & + & & \\
\hline Crocodylus porosus & $\mathrm{N}$ & $\mathrm{Y}$ & LC/Unknown & II & + & & & \\
\hline Varanus indicus & $\mathrm{N}$ & $\mathrm{Y}$ & LC/Unknown & II & & + & + & + \\
\hline Varanus prasinus & $\mathrm{N}$ & $\mathrm{Y}$ & LC/Stable & II & & + & & \\
\hline Elseya novaeguinea & $\mathrm{N}$ & $\mathrm{N}$ & LC/ Unknown & II & + & + & & \\
\hline Hypsilurus modestus & $\mathrm{N}$ & $\mathrm{N}$ & LC/Stable & & & & + & \\
\hline Hypsilurus dilophus & $\mathrm{N}$ & $\mathrm{N}$ & LC/Unknown & & & + & & + \\
\hline Morelia viridis & $\mathrm{N}$ & $\mathrm{Y}$ & LC/Stable & II & + & + & & + \\
\hline Morelia amethistina & $\mathrm{Y}$ & $\mathrm{N}$ & LC/Stable & II & & + & & \\
\hline Leiopython albertisii & $\mathrm{Y}$ & $\mathrm{N}$ & LC/Decreasing & II & & + & & \\
\hline Jumlah : & 3 & 5 & & 8 & 3 & 8 & 2 & 3 \\
\hline Asteropris turpicola & Y & $\mathrm{N}$ & LC/Stable & & + & + & & + \\
\hline Litoria amboinensis & $\mathrm{N}$ & $\mathrm{N}$ & LC/Stable & & + & + & & + \\
\hline Litoria genimaculata & $\mathrm{Y}$ & $\mathrm{N}$ & LC/Decreasing & & + & + & & + \\
\hline Platymantis papuensis & $\mathrm{N}$ & $\mathrm{N}$ & LC/Stable & & + & + & + & + \\
\hline Papurana arfaki & $\mathrm{N}$ & $\mathrm{N}$ & LC/Stable & & + & + & & + \\
\hline Papurana daemeli & $\mathrm{N}$ & $\mathrm{N}$ & LC/Stable & & + & + & & + \\
\hline Papurana grisea & $\mathrm{N}$ & $\mathrm{N}$ & DD/Unknown & & & & & + \\
\hline Jumlah: & 2 & 0 & & 0 & 6 & 6 & 1 & 7 \\
\hline
\end{tabular}

\section{Keterangan :}

P.106 2018 adalah Peraturan KLHK RI Nomor P.106 tahun 2018 tentang Jenis Tumbuhan dan Satwa Yang Dilindungi; IUCN (InternationalUnion for Conservation of Nature) adalah lembaga internasional yang bekerja untuk pelestarian spesies satwa dan tumbuhan. LC (Least Concern atau spesies dengan level resiko rendah); DD (Data Deficient atau kekurangan data); CITES (Convention on International Trade in Endangered Species of Wild Fauna and Flora)

ini di region Australia dan Amerika Utara meyakinkan bahwa family Hylidae berasal dari barat Gondwana. Dari 13 spesies Hylidae yang diduga berada pada area Kopermas KamiNassey, hanya ditemukan sebanyak empat spesies. Penelitian lainnya oleh Mayabubun (2010) di area HPHPT. Wanagalang Utama menemukan tiga spesies Hylidae lainnya yang tidak dijumpai dalam penelitian ini yaitu Litoria caerulea, L. gracilenta dan L. thesaurensis.

\section{F. Microhylidae (Katak Pohon, Tanah)}

Dari 12 spesies Microhylidae yang diduga berada pada areal Kopermas Kami-Nassey dijumpai hanya 6 spesies. Spesies Asterophrys turpicola, Xenorina sp., Austrochaperina sp., termasuk katak dari genus Oreopryne dan Hylophorbusmerupakan spesies endemik New Guinea. Banyak spesies dari family Microhylidae (subfamily Asterophrynae dan Genyophryinae) adalah endemic New Guinea (Allen Allison, 2006). 


\section{G. Ranidae (Katak Rawa, Sungai)}

Katak dari famili Ranidae di area Kopermas Kami-Nassey ditemukan hanya 6 spesies dari 10 spesies yang diduga ada.

- Genus Ranayang telah direvisi menjadi Papuranatelah dikenal 10 spesies (2 spesies adalah endemik untuk Papua) yang dalam penelitian ini hanya ditemukan 6 spesies. Kecuali Papurana daemeli yang tersebar juga di bagian northern Australia dan kepulauan Bismarck, ketiga spesies Papurana lainnya (P. papua, P. grisea danP. arfaki) merupakan spesies endemik New guinea termasuk Pulau Waigeo, Batanta dan Salawati).

- Genus Platymantisterdapat 10 spesies di Papua dan 5 spesies diantaranya adalah endemik Papua. Salah satu spesies endemik Papua yang tidak ditemukan dalam peneltian ini adalah $P$. punctata. Spesies ini ditemukan di area konsesi BP Tangguh (Kusrini \& Hasanah, 2007) dan di Pulau Waigeo.

\section{H. Crocodilidae (Buaya)}

Di dunia terdapat sebanyak 12 spesies buaya (McCoy, 2006). Terdapat dua jenis buaya di Papua yaitu Crocodilus porosus dan $C$. novaeguineae. Keduanyaspesies ini merupakan spesies lindungan. Buaya muara (C. porosus) walaupun masuk ke dalam apendik II CITES namun kini Indonesia menyepakati kuota ekspor nol dari penangkapan dan ekspor dapat berjalan jika peternakan hewan ini dapat memenuhi kuota yang diberikan. Dua spesies buaya terdapat di area Kopermas Kami-Nassey yakni Crocodylus novaguineae (buaya papua) dan Crocodylus porosus (buaya muara). Walaupun tidak disurvey secara terpisah namun dugaan kuat bahwa jenis buaya $C$. porosus (buaya muara) ada di habitat mangrove yang terkoneksi dengan lanskap kampung Idoor. Buaya C. porosus memiliki wilayah distribusi yang sangat luas meliputi India hingga SE Asia, Philipina, Timor, Pulau Caroline, New Guinea, Nort Australia, Pulau Solomon, New Hebrides dan Fiji (McCoy, 2006), sedangkan C. novaguineaea merupakan spesies endemik New Guinea (Allen Allison, 2006). Habitat kedua spesies buaya ini berbeda. $C$. novaeguineae hidup pada telaga, rawa-rawa dan sungai-sungai air tawar jauh hingga ke pedalaman dalam hutan New Guinea, sedangkan C. porosus hidup di muara-muara sungai, rawarawa hutan mangrove dan sering dijumpai di air asin. Sama halnya dengan spesies lainnya kedua buaya ini memiliki kemampuan adaptasi yang cukup tinggi sehingga buaya akan mampu bertahan (resisten) dengan gangguan hutan.

\section{Pythonidae (Ular Python)}

Famili ini memiliki 6 spesies di Papua dan hanya dijumpai 3 spesies dari 4 spesies yang diduga ada di area Kopermas Kami-Nassey. Hanya satu spesies dari famili iniyaituMorelia viridisyang dilindungi. Spesies Morelia viridis merupakan hewan nokturnal, arboreal (sering teramati di semak permukaan tanah) dan hidup di habitat hutan pada ketinggian 0-2000 mdpl (O'shea, 1996). $M$.viridis tersebar hingga ke Pulau Misol dan Aru, Cape York Peninsula dan far-northern Queensland. Populasi spesies ini sangat langka di alam (dalam penelitian ini hanya dijumpai satu individujuvenile). Dalam survei-survei serupa pada kawasan lainnya seperti di Merauke, Mamberamo, Waropen, Pegunungan Arfak dan kawasan lainnya di Papua spesies ular dari family Pythonidae sangat langka dijumpai. Diperkirakan bahwa populasi M. viridis di area Kopermas KamiNassey tidak lebih dari 30 individu.

Dua spesies endemik New Guinea dari famili ini adalah ular Apodora papuana dan Morelia boeleni yang tidak dijumpai dalam penelitian ini. Hingga saat ini belum ada laporan tentang penyebaran ular $A$. papuanadi daerah Teluk Wondama maupun Teluk Bintuni. Namun demikian, Oshea (1996) menginformasikan bahwa A. papuana juga tersebar di bagian utara dan barat Papua termasuk di Pulau Biak dan Pulau Misol. Oleh karena itu diduga bahwa spesies ini ada juga di area Kopermas KamiNassey, sedangkan M. boeleni tidak ada karena penyebarannya di atas ketinggian 1000-2000 mdpl. Ular A. papuana hidup pada lowland monsoon, savanna-woodlands dan savanna.

Walaupun spesies dari famili Pythonidaedapat beradaptasi dengan gangguan hutan namun kondisi populasinya sangat rawan jika spesies-spesies satwa ini sering dibunuh baik sengaja maupun tidak sengaja. Morelia viridis adalah spesies yang sering diperjualkan sebagai hewan pelihara, namun saat ini hal tersebut tidak terjadi di area Kopermas Kami-Nassey. 


\section{J. Agamidae (Bunglong)}

Tiga spesies yang ditemukan dalam penelitian ini sudah bukan merupakan spesies lindungan menurut Permen KLHK P.106 2018. Sebelumnya Hypsilurus dilophus (Bunglong sisir) dilindungi oleh PP 7 tahun 1999. Spesies endemik New Guinea lainnya yang ditemukan adalah $H$. papuensis yang juga ditemukan di hutan berbukit Haya, Mamberamo (Krey, 2010). Di Australia genus Hypsilurus terdiri dari hanya dua spesies (Witten 1993) sedangkan di New Guinea terdapat sekitar 12 spesies dan sebanyak 8 spesies berada di Papua dimana 4 spesies diantaranya yang tidak ditemukan dalam penelitian ini adalah endemic Papua (Allison, 1996) .H. dilophusdijumpai juga pada survey di area konsesi BP Tangguh dan PT. Wananggalang Utama. $H$. dilophus juga di temukan di hutan dataran rendah sekitar Pegunungan Arfak dan Tamrauw, Pulau Waigeo, Gesa (Waropen) dan Mamberamo hingga ke wilayah PNG.

\section{K. Chelidae (Kura-kura)}

Sebanyak satu spesies (Elseya novaeguineae) dari famili Chelidae dijumpai dalam penelitian ini. Telah diketahui terdapat enam spesies kura-kura Chelidae di Papua. Semua spesies ini dijumpai menghuni rawa atau sungai yang alirannya lambat di bagian Selatan kecuali E. novaeguineae yang tersebar di Utara (Allison 2007). E. novaeguineae merupakan spesies endemik New Guinea yang tersebar di bagian Utara Papua, Pulau Waigeo, Pulau Serui termasuk di Danau Sentani hingga bagian utara PNG. Spesies ini juga ditemukan oleh Maturbongs (2006) di Sungai Nanimori Teluk Wondama. E. novaeguineae tergolong tidak umum ditemukan walaupun spesies ini tersebar luas hingga ke wilayah Utara Papua. Selain aktifitasnya yang sangat pekah terhadap gangguan, populasi di alam sangat sedikit sehingga spesies ini jarang ditemukan (Krey \& Burwos, 2019).

\section{Varanidae (Biawak)}

Sebanyak dua spesies (Varanus indicus, dan $V$. prasinus) dijumpai dalam penelitian ini. Spesies-spesies ini umum di Papua namun sangat jarang dijumpai di arealKopermas KamiNassey. Walaupun bukan merupakan spesies endemik Papua (termasuk PNG dan Australia) namun dua spesies ini dilindungi oleh PP
Nomor 106 tahun 2018.

Sebanyak 11 spesies telah dikenal di Papua diantaranya terdapat 4 spesies endemic Papua yaitu V. boehmei (endemik Pulau Waigeo), V. kordensis (Endemik Pulau Biak), V. macraei (diketahui hanya dari Pulau Batanta) dan $V$. reisingeri (endemik Pulau Misol) sedangkan sisanya memiliki zoogeography hingga PNG, Australia dan Micronesia (khusus V. indicus) (Hoser, 2013). Varanus doreanusditemukan menghuni dataran rendah Papua termasuk Pulau Salawati dan Pulau Biak pada hutan monsoon dan hutan primer, seperti mixed alluvial forest dan mixed hill forest (Allison 2007). Dalam penelitian ini $V$. doreanus dijumpai pada hutan sekunder berbukit dan diduga spesies ini ada pada hutan primer di areal Kopermas Kami-Nassey.

Varanus indicus juga dijumpai di Tangguh bersama dengan biawak endemik New Guinea (termasuk Pulau Salawati) Varanus salvadorii (CITES II). Diduga spesies ini (V. salvadorii) ada di area Kopermas Kami-Nassey. Philip dan Philip (2007) menjelaskan bahwa $V$. salvadorii biasanya hidup pada vegetasi rainforest seperti tipe hutan mixed alluvial dan mixed hill sertahutan riparian. Spesies Varanus prasinusmenghuni pohon-pohon pada hutan hujan dataran rendah dan hutan riparian. Kanopi hutan yang tetap tersambung terutama pada jalur-jalur tarik akan membantu mobilisasi spesies-spesies ini. Spesies Varanus yang ditemukan dan juga yang diduga ada di areal Kopermas Kami-Nassey dapat dijadikan sebagai bio indikator perubahan kualitas habitat.

\section{Scincidae (Kadal)}

Seluruh spesies dari family ini belum dilindungi oleh Peraturan Indonesia. Sebelumnya dalam PP Nomor 7 tahun 1999 satu-satunya spesies lindungan adalah kadal Tiliqua gigas, namun dalam P.106 tahun 2018 telah dikeluarkan dari daftar spesies lindungan. Spesies kadal lainnya yang ditemukan dalam penelitian ini yakni kadal dari genus Emoia, Sphenomorphus, dan Lamprolephis. Rendahnya jumlah spesies kadal yang dijumpai dalam penelitian ini lebih disebabkan faktor sedikitnya waktu penelitian tersedia. Banyak spesies kadal merupakan spesies endemik New Guinea (mainland). Daerah penyebaran mereka hingga PNG (Brown, 1991). 


\section{N. Gekkonidae (Tokek)}

Sebanyak satu spesies yakni Hemidactylus frenatus jumpai dalam penelitian ini dari sekitar 13 spesies yang diduga ada dalam areal Kopermas Kami-Nassey. Dalam penelitian ini tidak dijumpai Cyrtodactylus irianjayaensis (spesies endemik Papua). Namun demikian diduga spesies ini ada di areal Kopermas KamiNassey. Spesies C.irianjayaensis juga dijumpai di area hutan sekunder PT. Wanagalang. Seluruh spesies dari famili Gekkonidae merupakan spesies nokturnal. Taksa ini sering dijumpai menghuni batang dan cabang pohon, semak di hutan dataran rendah bahkan beberapa spesies dijumpai pada bebatuan serta batang pohon yang telah terurai di atas tanah. Spesies dari famili ini memilih tempattempat yang kering dan tertutup dari cahaya matahari sehingga dapat dijadikan sebagai indiator dalam pengelolaan hutan. Di area ekskopermas spesies dari famili Gekkonidae tidak dijumpai selama penelitian, diduga akibat kondisi habitat yang sudah tidak menunjang. Beberapa spesies memiliki nilai ekonomi yang tinggi sehingga monitoring dan pengawasan terhadap aktifitas penangkapan saat ini dan dimasa mendatang sangat penting dilakukan untuk mempertahankan populasi di alam.

\section{KESIMPULAN}

Seluruhnya kawasan hutan dalam areal Kopermas Kami-Nassey sangat penting bagi 16 spesies katak dan 20 spesies reptil yang dijumpai saat ini. Dalam areal Kopermas KamiNassey tidak dijumpai satupun spesies yang termasuk kategori Vurnerable, Endagered, maupun Critically endegered. Namun demikian beberapa spesies termasuk kategori Apendik II CITES buaya $C$. porosus dan C. novaeguineae, biawak Varanus spp, testudinata Elseya novaeguinea, Leiopython albertisii, Morelia viridis dan Morelia amethistina. Kebanyakan spesies yang dijumpai maupun yang diduga ada dalam area konsesi areal Kopermas KamiNassey merupakan spesies endemik New Guinea termasuk pulau-pulau sekitar.

\section{UCAPAN TERIMA KASIH}

Penelitian ini adalah bagian dari proyek penilaian High Conservation Value (HCV) dalam rangka mendukung pembangunan berkelanjutan di Tanah Papua. Seluruhnya biaya penelitian ini dan fasilitas selama di lapangan ditanggung oleh Koperasi Masyarakat Adat Kami-Nassey. Ucapan trima kasih yang tak terhingga kami sampaikan.

\section{Daftar Pustaka}

Allison, Alen. (1996). Zoogeographo of Ambhibins and Reptiles of New Guinea and the Pacific Region (pp. 407-436). http://www.botany.hawaii.edu/basch/ uhnpscesu/pdfs/sam/Allison1996AS.pdf

Allison, Allen. (2006). Reptiles and Amphibians of the Trans-Fly Region, New Guinea. http://pbs.bishopmuseum.org/pdf/transfly-r.pdf

Brown, W. C. (1991). Lizards of the Genus Emoia (Scincidae) with Observations on their Evolution and Biogeography. Memoirs of the California Academy of Sciences., 15, 1-94. https://www.biodiversitylibrary. org/part/74985

Günther, R., Richards, S., Tjaturadi, B., \& Krey, K. (2015). Two new species of the genus Cophixalus from the Raja Ampat Islands west of New Guinea (Amphibia, Anura, Microhylidae). Zoosyst, 91(2), 199-213. https://doi.org/10.3897/zse.91.5411

Harry Hines, J.-M. H. E. M. D. N. (2004). Litoria Freycineti. https://www.iucnredlist.org/ species/41033/10391425

Hoser, R. T. (2013). Monitor Lizards reclassified with some commonsense (Squamata: Sauria: Varanidae). Australasian Journal of Herpetology, 21(Oktober), 41-58. http://www.smuggled.com/issue-21pages-41-58.pdf

Krey, K. (2010). Ektoparasit Acarina pada Kulit Sisik Ular Putih (Micropecis Ikaheka) dari Manokwari. Jurnal Natural, 9(1). https:// doi.org/10.30862/jn.v9i1.777

Krey, K. (2019). Kasuri Block High Conservation. Deepublish.

Krey, K., \& Burwos, H. (2019). Herpetofauna Fak Fak. Prosiding Seminar Nasional MIPA UNIPA, 4(1), 11-28. https:// prosiding.fmipa.unipa.ac.id/index.php/ SNMIPAUNIPA/article/view/26

Kusrini, M., \& Hasanah, A. (2007). Herpetofauna di Areal Konsesi BP LNG Tangguh dan Babo, Teluk Bintuni, Рapua. Institut Pertanian Bogor. 
Mayabubun, B. L. M. (2010). Inventarisasi Jenis Amphibi di sekitar Teluk Bintuni. Universitas Negeri Papua.

McCoy, M. (2006). Reptiles of the Solomon Islands. Coronet Books Incorporated.

O'shea, M. (1996). A Guide to the Snakes of Papua New Guinea (1st editio). Independent Pub.

Oliver, P., Tjaturadi, B., Mumpuni, Krey, K., \& Richards, S. (2008). A New Species of Large Cyrtodactylus (Squamata: Gekkonidae) from Melanesia. Zootaxa 1894, Oktober,
59-68. http://www.academia.edu/ download/32720481/cyrtodactylus_zugi. pdf

Philipp, K., \& Philipp, D. (2007). The Monitor Lizards of Papua (The Ecolog). Periplus editions.

Richards, S. J., Iskandar, D. T., \& Tjaturadi, B. (2002). Amphibians and reptiles of the Dabra Area, Mamberamo River Basin, Papua, Indonesia. Conservation International RAP Bull, 25(9), 69-79. 